\section{Carroceiros e metrópoles no século XXI}

\section{Costa, Tânia Mara Borges da}

Doutoranda e Membro do Grupo de Estudos, Pesquisa e Extensão em Políticas Públicas, Direito à saúde e Bioética BIOGEPE. da Faculdade de Direito de Vitória (FDV). Email: tborgesdacosta@gmail.com

\section{Bussiguer, Elda Coelho de Azevedo}

Livre Docente pela Universidade do Rio de Janeiro UniRio. Doutora em Bioética pela Universidade de Brasília - UnB. Mestre em Direitos e Garantias Fundamentais pela Faculdade de Direito de Vitória - FDV. Coordenadora do Programa de Pós-Graduação em Direito da Faculdade de Direito de Vitória - FDV. Editora da Revista Direitos e Garantias Fundamentais (QUALIS A 1). Coordenadora do Grupo do BIOGEPE - Grupo de Estudos, Pesquisa e Extensão em Políticas Públicas, Direito à saúde e Bioética. Membro do Conselho científico da Sociedade Brasileira de Bioética.

\section{PALAVRAS-CHAVE: Direitos Sociais; Carroceiros}

INTRODUÇÃO: Toda forma de vida é única e merece ser respeitada, qualquer que seja a sua utilidade para o homem, e, com a finalidade de reconhecer aos outros organismos vivos este direito, o homem deve se guiar por um código moral de ação (ONU-RESOLUÇÃO 37/82). Sob esta lente De Souza Abreu e Bussinguer (2013) analisam que o pensamento holístico é pautado na ideia de meio ambiente como sistema integrado único. Neste sentido, o objetivo aqui é refletir sobre a categoria dos Carroceiros e seus reflexos sócio-ambientais, nas grandes cidades. O método utilizado é o dialético qualitativo documental, com dados extraídos da municipalidade de Vila Velha/ES. Os resultados evidenciam ausência estatal, abuso de animais, acidentes em rodovias com morte de animais e humanos, atividades criminosas, miséria qualificada, exclusão social, inexistência dos Direitos e Garantias Fundamentais. Denúncia de exploração de animais de tração, inclusive na extração irregular de areia, em regiões de reserva ambiental, atividade ilícita e criminosa, realizada pela Sociedade Protetora dos Animais do Espírito Santo (SOPAES), entidade filantrópica, a qual objetiva resgate de animais abandonados, tratamento, vacinação, castração, adoção, educação e conscientização sobre: posse responsável, abandono, maus-tratos, valorização e compaixão e o respeito pelos animais e o meio ambiente, reconhecendo a interdependência entre todos os seres vivos, assim como uma compreensão mais crítica e questionadora do mundo. E contabiliza 8 toneladas de ração doadas, 1.200 animais adotados,760 castrados, em média mensal 880 consultas, além de outras participações coletivas. Da denúncia resultou reunião da SOPAES com Ministério
Público Estadual e a Prefeitura Municipal de Vila Velha representada pela Secretaria de Meio Ambiente, Secretaria Municipal de Assistência Social e Secretaria Municipal de Desenvolvimento Econômico, em 25/09/18 na Promotoria de Justiça Cível de Vila Velha. Buscou-se solução para esta realidade que envolve questões sociais de natureza múltiplas e, decidindo-se em Ata MPES NF 2018.0017.6068-03: a) A proteção animal, fazer cessar o uso dos mesmos. b) Atividades das pessoas e famílias que sobrevivem dessa "atividade ilícita", com inclusão, capacitação para o desenvolvimento de atividade que proporcione renda, sob Projeto Piloto mediante parceria (só 2019 haverá inclusão orçamentária para Políticas Públicas específicas em 2010). Conclui-se que esta realidade retrata a Administração Pública Brasileira, na medida em que se desconsidera as regras e os princípios constitucionais. Que sob análise epistemológica da linguagem em Bussinguer, Coura e Abreu (2017), "insere-se a crítica ao discurso político-ideológico que sustenta a expressão "desenvolvimento sustentável". Enfrentar esse desafio implica em aproximar-se de uma corrente filosófica que vislumbra a linguagem não como fenômeno natural do homem, isto é, detentora de um sentido que lhe é imanente, mas como decorrência de um contexto discursivo de permanente tensionamento dos poderes sociais". Exigindo, portanto da Bioética associação ao Biodireito, na condução de relações sócio-jurídicaeconômicas multivalentes. Doutra sorte, Costa (2015) observa que há utopia prevalente com as normas vigentes, pelo elevado grau de vulnerabilidade e impotência desta categoria: "mais de mil famílias de carroceiros desamparadas, sem o mínimo existencial para uma vida digna”, contra "forças da cidade, em pleno séc. XXI".

\section{REFERÊNCIAS}

\section{[1] DE SOUZA ABREU, Ivy; DE AZEVEDO}

BUSSINGUER, Elda Coelho. Antropocentrismo, ecocentrismo e holismo: Uma breve análise das escolas de pesamento ambiental. Derecho y Cambio Social, v. 10, n. 34, p. 25, 2013.

[2] BUSSINGUER, Elda Coelho de Azevedo; COURA, Alexandre de Castro; ABREU, Yvy de Souza. limites e possibilidades do ativismo judicial no Estado Democrático de Direito RIHJ: uma análise da arguição de Descumprimento de Preceito Fundamental n. 54. Revista do Instituto de Hermeneutica Jurídica - RIHJ, BH, ano 15, n. 21, p. 153-169, jan/ju. 2017.

[3] PMES - Promotoria de Justiça Cível de Vila Velha - Ata de Reunião MPES NF 2018.0017.6068-03.

[4] COSTA, Tânia Mara Borges da. (2015). CLAD 00817.11 - Conselho de Saúde: participação social e democracia mais que utopia / Costa, Tânia Mara Borges da. - Vitória: Escola Superior de Ciências da Santa Casa de Misericórdia de Vitória, 2015. - 11 p. Evento: Congresso Internacional del CLAD sobre la Reforma del 
Estado y de la Administración Pública, 20 - Documento

Libre (2015 Nov. 10-13: Lima). - CLAD. 